\title{
Deformation superposition effect of asphalt mixture based on experiments and micromechanical modeling
}

\author{
Chun $\mathrm{Li}^{1}$, Xinxing Bian ${ }^{2}$, Qifeng Dong ${ }^{2}$ and Huining $\mathrm{Xu}^{2^{*}}$
}

\begin{abstract}
Under multi-wheel heavy load, the asphalt mixture is prone to exhibit the deformation superposition effect, which exacerbates the damage of pavement structure. Multi-point penetration tests and numerical simulations by discrete element method (DEM) are performed to investigate the deformation superposition effect and micromechanical characteristics of asphalt mixture. The effect of wheel spacing, wheel group, and the evolution of micromechanical deformation superposition behavior are analyzed. Results indicate that the deformation superposition resistance of the asphalt mixture under the multi-wheel load decreases dramatically with the decrease in wheel spacing and the increase in the number of wheels, specifically the wheel spacing is $54 \mathrm{~mm}$ and the number of wheels is 4 . The DEM simulations reflect the micromechanical property of asphalt mixture in the multi-point penetration test. The reduction of tensile chains is the internal reason for asphalt mixture deformation superposition, indicating the decrease of the adhesive strength of the material. A remarkably positive correlation is found between the reduction of the tensile chain and the deformation effect coefficient. In the process of superposition, the aggregate skeleton force chains are gradually destroyed and decrease to zero until cracking. The numerical simulation outcome is consistent with the laboratory penetration test outcome.
\end{abstract}

\section{Highlights}

(1) Evaluation of deformation superposition behavior of asphalt mixture by the multi-point penetration test.

(2) Determinant of the deformation superposition resistance of the asphalt mixture under the multi-wheel load is wheel spacing and the number of wheels.

(3) The reduction of tensile chains is the internal reason for asphalt mixture deformation superposition.

(4) The numerical simulation method can reflect the laboratory penetration test outcome.

Keywords: Asphalt mixtures, Deformation superposition effect, Multi-point penetration test, Discrete element method (DEM), Micromechanical characteristics

\footnotetext{
${ }^{*}$ Correspondence: xuhn@hit.edu.cn

${ }^{2}$ School of Transportation Science and Engineering, Harbin Institute

of Technology, Harbin 150090, China

Full list of author information is available at the end of the article
}

\begin{abstract}
Introduction
The proportion of multi-wheel heavy transportation increases significantly on asphalt pavements of highgrade highways and airports. The multi-wheel load produces stress interference inside the asphalt mixture. The deformation that occurs at the same point is equivalent to the deformation superposition caused by a single load. Deformation superposition accelerates pavement
\end{abstract}


structure destruction and performance degradation [13]. Excessive superposition deformation directly affects driving comfort and endangers driving safety. Therefore, the first step is to understand the evolution of deformation superposition under the multi-wheel load and internal micromechanical characteristics that uncover the deformation superposition behavior to effectively control the deformation and ensure the long-term stability of pavement structure.

The importance of deformation superposition related to heavy load as the major contributor to damage of asphalt pavement has long been recognized $[4,5]$. On the one hand, previous studies mainly focused on long-term monitoring and field investigation of the macroscopic characteristics of deformation superposition. Gomezramirez [6], Hayhoe et al. [7], and Gopalakrishnan [8] utilized the National Airport Pavement Test Facility to monitor the damage of asphalt pavement under aircraft load. The mechanical response within pavement materials under the multiple wheels is obtained. Al-Qadi et al. [9] embedded 149 sensors on the airport pavement. The sensors monitor the response of pavement structure and ambient data under vehicles and aircraft. The data are used to modify pavement design models and performance estimates. Fabre et al. [10] established a test section at an airport. They set up a rutting monitoring sensor to explore the pavement response under two-wheel load. Salama et al. [11], Zhao et al. [12], and Minkwan et al. [13] analyzed the superposition effect of asphalt pavement under the multi-axle loads. They pointed out that the asphalt pavement responses appear to have obvious superposition characteristics, indicating that the superposition under multi-wheel load must be considered compared with single wheel loads. These studies confirm the existence and destructive effect of deformation superposition behavior of asphalt mixture. However, most field monitoring is time-consuming and involves considerable financial costs. Understanding the micromechanical mechanism of the deformation superposition behavior of asphalt mixture based on field monitoring is difficult.

On the other hand, understanding the deformation superposition characteristics conduces to predict the structural response of pavement and provides a method to design or repair asphalt pavement. Thompson et al. [14] proposed two superposition analysis methods. The whole idea relies on the assumption of the linear superposition principle. They [15] also applied the superposition principle to analyze the superposition effect. They believed that the pavement response under multi-wheel load can be obtained by superimposing the response under a single wheel load. Zhao et al. [16] used the peak midpoint method to calculate the typical pavement structure damage under dual-wheel load. The damage obtained by diverse methods differs by more than three times. Martin [17], Marques et al. [18], Chatti et al. [19], and Homsi et al. [20] reached similar conclusions. This condition indicates that the prediction of superposition response under the multi-wheel load is based on the superposition principle. However, this assumption is not found in the understanding of the internal mechanism of materials, and expounding scientifically on the pavement damage under complex loads is difficult.

The discrete element method (DEM) allows the deformation of asphalt mixture to be characterized from a microscale perspective. You et al. [21] established a 2D model of the tensile tests for asphalt mixture. They analyzed the distribution of forces and the expansion of cracks. Zelelew [22] simulated the compression creep test of asphalt mixture by utilizing a 2D discrete element microscopic model from X-ray computed tomography images. He obtained the flow number and creep compliance and analyzed the permanent deformation characteristics of asphalt mixture. Chen et al. [23, 24] studied the deformation of asphalt mixture in the compaction process by utilizing the DEM. They discussed the void distribution and obtained similar results with the experiment. The results indicate that simulating the meso mechanical behavior by reconstructing a discrete element model of asphalt mixture is feasible. The DEM can quantitatively analyze the force chain distribution of asphalt mixture during loading. The force chain is used to describe the interaction of particles within the system. This concept was proposed by Bouchaud et al. [25], Wittmer et al. [26] on the basis of the study of arching effect, stress distribution, and stress extension in granular matter. Tordesillas et al. [27, 28] utilized a discrete element model to analyze the spatial distribution of force chain buckling under quasi-static biaxial load. Wang et al. [29] considered the influence of the filling rate and friction coefficient of dense particulate on the distribution of force chain. They studied the angle distribution of the force chain. You et al. $[30,31]$ established a discrete element model of asphalt mixture composed of particles to simulate the standard penetration test. They presented the distribution of force chains among aggregate, among asphalt mastics, and between aggregate and asphalt mastics at different loading times.

In conclusion, the deformation superpositioninduced damage contributes considerably to the deterioration of asphalt mixtures. Several studies rarely focused on the micromechanical characteristics of the deformation superposition behavior of asphalt mixture based on field monitoring. The DEM promotes the understanding of the internal micromechanical of asphalt mixture deformation superposition. Further 
research is necessary. In this study, the multi-point penetration test and DEM were used. The macro characteristics of the asphalt mixture deformation effect were analyzed, and the mesoscopic mechanism of deformation superposition was explored. The matching relationship between macroscopic deformation and micromechanical was established, providing the necessary guidance for the prevention and treatment of asphalt pavement deformation superposition.

\section{Materials and experimental methods \\ Asphalt mixtures}

According to the Marshall mix design method, a stone matrix asphalt mixture, SMA-13, was manufactured for the test. Aggregate gradation with the nominal maximum aggregate size of $13.2 \mathrm{~mm}$ was demonstrated in Fig. 1 . The aggregate was andesite produced in Heilongjiang Province, the properties of the aggregate were shown in Table 1 and Table 2, tests were conducted to find the properties of coarse aggregate and fine aggregate according to the Test Methods of Aggregates for Highway Engineering (JTG E42-2005). The filler was limestone with an apparent relative density of 2.720 , to enhance the anti-stripping ability of the asphalt mixture. The asphalt was from China National Petroleum Corporation with a penetration grade of $80 / 100$. Based on the Standard Test Methods of Bitumen and Bituminous Mixtures for Highway Engineering (JTG E20-2011), the properties of the SMA-13 mixture were determined as shown in Table 3.

Specimens were prepared by a gyratory compactor with standard vertical pressure of $0.6 \mathrm{MPa}$, a gyratory angle of $1.25^{\circ}$, and a gyratory speed of $30 \mathrm{rpm}$. The initial diameter of the specimen was $150 \mathrm{~mm}$, the height was $170 \mathrm{~mm}$. Then, considering the requirements for parallel tests, the specimens were cut from the middle and performed the same test. Thus, the final specimen used in the test was $85 \mathrm{~mm}$ in height and $150 \mathrm{~mm}$ in diameter.

\section{Multi-point penetration test}

In previous work [32], the penetration test was proven to simulate the stress state of asphalt pavement. However, the traditional uniaxial penetration test cannot accurately describe the mechanical behavior of asphalt mixture under multi-wheels. Thus, the multi-point penetration test was developed to characterize the deformation superposition effect of asphalt pavements under multi-wheel load.

The apparatus used in this study is shown in Fig. 2. It can be used for multi-point penetration tests in the condition of various spacing. This apparatus consists of the main shaft, disk, and penetration loading shaft. The height of the penetration loading shaft is $100 \mathrm{~mm}$, and the diameter is $20 \mathrm{~mm}$. The size of the disk is shown in Fig. 3. The central hole was used for uniaxial loading. The bar-type holes were used for two-point loading, which can simulate the condition of the distance between 60 and $120 \mathrm{~mm}$. The inner or outer circular holes were used for four-point loading. The distance between the inner holes is $60 \mathrm{~mm}$, and the distance between the outer holes is $68 \mathrm{~mm}$. Different combinations of holes can be used to simulate six-point and eight-point loading with $60 \mathrm{~mm}$ or $68 \mathrm{~mm}$ wheel spacing.

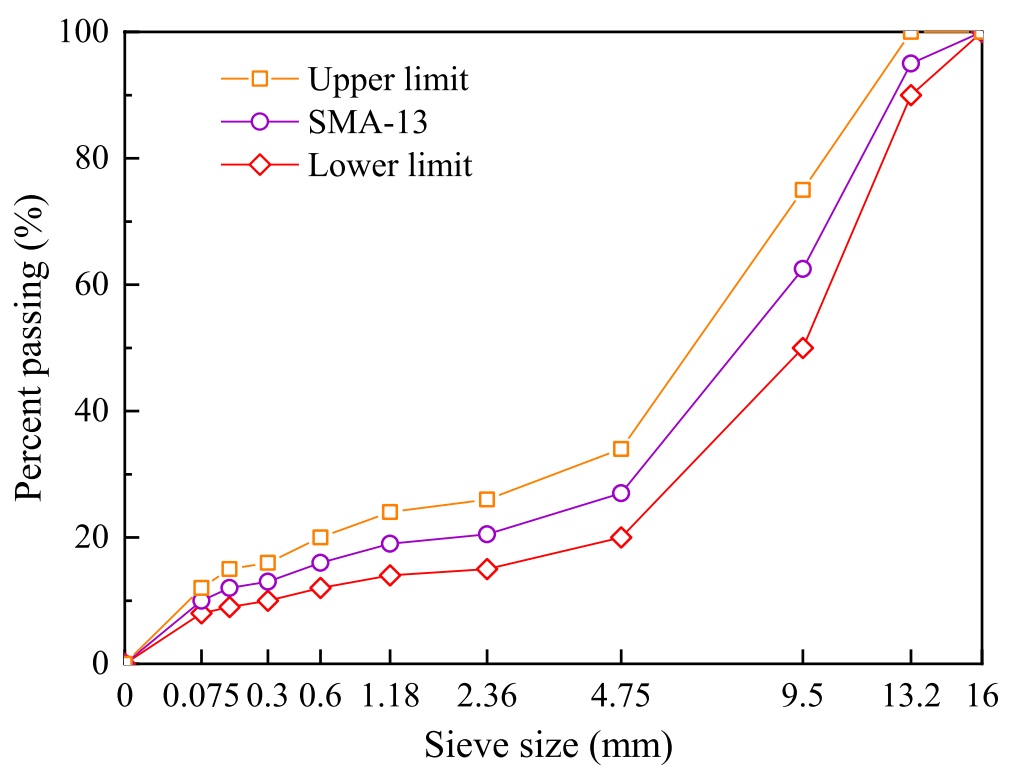

Fig. 1 Aggregate gradation curves for SMA-13 mixtures 
Table 1 Basic properties of coarse aggregate

\begin{tabular}{lllllll}
\hline Index & \multicolumn{3}{l}{ Sieve Size / $\mathbf{~ m m}$} & & Requirement \\
\cline { 2 - 5 } & $\mathbf{1 3 . 2}$ & $\mathbf{9 . 5}$ & $\mathbf{4 . 7 5}$ & $\mathbf{2 . 3 6}$ & \\
\hline Bulk specific gravity & 2.775 & 2.782 & 2.773 & 2.772 & $\geq 2.60$ \\
Water Absorption / \% & 0.50 & 0.49 & 0.57 & 0.51 & $\leq 2.0$ \\
Crushing Value / \% & 10.1 & & & & $\leq 26$ \\
Los-Angeles Abrasion / \% & 14.5 & & & & $\leq 28$ \\
\hline
\end{tabular}

The loading device used is a universal testing machine (UTM-250). The equipment installation is shown in Fig. 4 . In the test, the specimens were placed in a temperature-controlled chamber for at least $3 \mathrm{~h}$, the temperature was set at $60^{\circ} \mathrm{C}$. The specimen was then placed on the loading platform, the rubber mat was pasted below the penetration shaft, and the penetration shaft was lowered until it contacted the specimen, the contact force is 0.200 $\mathrm{kN}$. The UTM-250 performed with strain control mode and obtained the data pair that the loading force varied with the loading depth. The penetration shear curve is shown in Fig. 5. The loading stress converted from the loading force is the ordinate, and the penetration depth is the abscissa.

In this analysis, the superposition effect coefficient was used to evaluate the deformation superposition characteristics of asphalt mixture. The superposition effect coefficient is sensitive to the type of asphalt mixtures and has a strong correlation with the dynamic stability obtained from the rutting test [33]. This condition indicates that this coefficient can correctly evaluate the influence of asphalt mixture type on the deformation superposition effect under multi-point load and connect well with the asphalt pavement deformation under a wheel load. The smaller superposition effect coefficient demonstrates that the superposition deformation of the asphalt mixture increases significantly, and the material has weak resistance to multi-wheel load. The superposition effect coefficient is calculated by using Eq. (1).

$$
\beta_{\Delta}=\frac{\Delta_{1}}{\Delta_{\mathrm{n}}},
$$

Where $\Delta_{1}$ is the penetration load growth rate under the uniaxial load, $\Delta_{\mathrm{n}}$ is the penetration load growth rate under the multi-point load. In particular, the penetration load growth rate refers to the slope of the linear growth section, it means the load growth of the asphalt mixture at a penetration depth of $1 \mathrm{~mm}$.

\section{Discrete element model}

The 3D skeleton model of the SMA-13 mixture was established to investigate the micromechanical characteristics of the deformation superposition effect. The skeleton particles were the main load-bearing elements of the asphalt mixture. This study adopted a spherical composite body with four grades of 2.36-4.75, 4.75-9.5, 9.5-13.2, and $13.2-16 \mathrm{~mm}$ to simulate the skeleton model of the asphalt mixture. The model contained 681 sphere units in total. The gradation and size of the skeleton model were consistent with the asphalt mixture used in the test. The voids of coarse aggregate were regarded as the porosity of the skeleton model.

The bonding behavior of skeleton particles was simulated by using a parallel-bonded contact model on a certain scale. Within the cylinder of two spherical particles, the connection of asphalt and aggregate according to real asphalt mixture was built. This connection can accurately represent the composition of the asphalt mixture, avoid setting the bonding properties of each element of the asphalt mixture, and resolve the problems of slow computing speed and difficult convergence. The parallelbonded contact model parameters used in this study are shown in Table 4.

Under penetration load, a wall with a diameter of $20 \mathrm{~mm}$ and a length of $50 \mathrm{~mm}$ was established to simulate the shaft, and a wall with a side length 4 times the diameter of the skeleton model was established to simulate the platform. The stiffness of the shaft and platform was $1 \times 10^{8} \mathrm{~N} \cdot \mathrm{m}^{-1}$. The skeleton particle model under uniaxial and four-point penetration load is shown in Fig. 6.

\section{Results and discussion}

Failure mode of deformation superposition effect

Previous studies showed that the shear failure mode of the asphalt mixture in the uniaxial penetration test is similar to that of pavement core [34]. However, the uniaxial penetration method cannot accurately describe the superposition damage of asphalt pavement. On the basis

Table 2 Basic properties of fine aggregate

\begin{tabular}{llllll}
\hline Index & \multicolumn{2}{l}{ Sieve Size / mm } & & Requirement \\
\cline { 2 - 6 } & $\mathbf{1 . 1 8}$ & $\mathbf{0 . 6}$ & $\mathbf{0 . 3}$ & $\mathbf{0 . 1 5}$ & $\mathbf{0 . 0 7 5}$ \\
\hline Apparent specific gravity & 2.771 & 2.755 & 2.772 & 2.778 & 2.783 \\
Angularity / s & 45 & & & & \\
\hline
\end{tabular}


Table 3 The properties of the SMA-13 mixture

\begin{tabular}{llllll}
\hline $\begin{array}{l}\text { Asphalt } \\
\text { content(\%) }\end{array}$ & $\begin{array}{l}\text { Volume } \\
\text { of air } \\
\text { voids(\%) }\end{array}$ & $\begin{array}{l}\text { Voids in } \\
\text { mineral } \\
\text { aggregate(\%) }\end{array}$ & $\begin{array}{l}\text { Voids } \\
\text { filled with } \\
\text { asphalt(\%) }\end{array}$ & $\begin{array}{l}\text { Marshall } \\
\text { stability(kN) }\end{array}$ & $\begin{array}{l}\text { Flow } \\
\text { value(mm) }\end{array}$ \\
\hline 6.5 & 4.0 & 18.5 & 78.4 & 7.6 & 4.3 \\
\hline
\end{tabular}

of the method mentioned in Multi-point penetration test Section, uniaxial and four-point penetration tests were conducted for SMA-13 with a temperature of $60^{\circ} \mathrm{C}$ and a loading rate of $1 \mathrm{~mm} / \mathrm{min}$. This process was performed to obtain and compare the failure mode of the asphalt mixture. The penetration curve is shown in Fig. 7.

As shown in Fig. 7, the load growth rate under uniaxial and four-point penetration of the SMA-13 mixture is 4.33 and $2.50 \mathrm{MPa} / \mathrm{mm}$ respectively. This finding indicates that resisting deformation under a four-point penetration load is more difficult for the asphalt mixture.

A direct result is shown in Fig. 8, which illustrates the crack patterns of asphalt mixture under uniaxial and four-point loads.

Under uniaxial penetration load, the cracking path is from the center to the edge of the specimen, indicating that the edge cracking is the main reason for the strength loss of the mixture. Under four-point penetration load, the crack path is the edge of the specimen and the connecting line of the four penetration points, indicating that the deformation is caused by the joint action of four penetration shafts. The deformation appears as a superposition phenomenon. This condition results in considerable cracking of the sample. Thus, the resistance to deformation decreases, and the load growth rate is small. Specifically, $\Delta_{4}$ is less than $\Delta_{1}$, and the superposition coefficient is less than 1 .

\section{Effect of the wheel group on deformation superposition}

The impact of wheel spacing and the number of wheels on the superposition effect in asphalt mixtures is quantitatively discussed to investigate the external cause of the deformation superposition in asphalt mixtures.

\section{Effect of wheel spacing}

Wheel spacing is regarded as the key factor affecting the deformation behavior of asphalt mixture. This section quantificationally examines the influence of wheel spacing on the deformation superposition effect of the SMA-13 mixture by using the aforementioned test method. The four-point penetration tests with the wheel spacing of 54,60, and $65 \mathrm{~mm}$ were conducted, the loading rate was $1 \mathrm{~mm} / \mathrm{min}$, and the test temperature was $60^{\circ} \mathrm{C}$. The results from the various wheel spacings exhibit the variation of superposition parameters, as shown in Figs. 9 and 10.

Figure 9 presents the penetration load growth rate in uniaxial and four-point penetration tests. On the whole, the penetration load growth rate generated by the uniaxial penetration is greater than that by the four-point. The result of uniaxial penetration is $1.1 \mathrm{MPa} / \mathrm{mm}$,

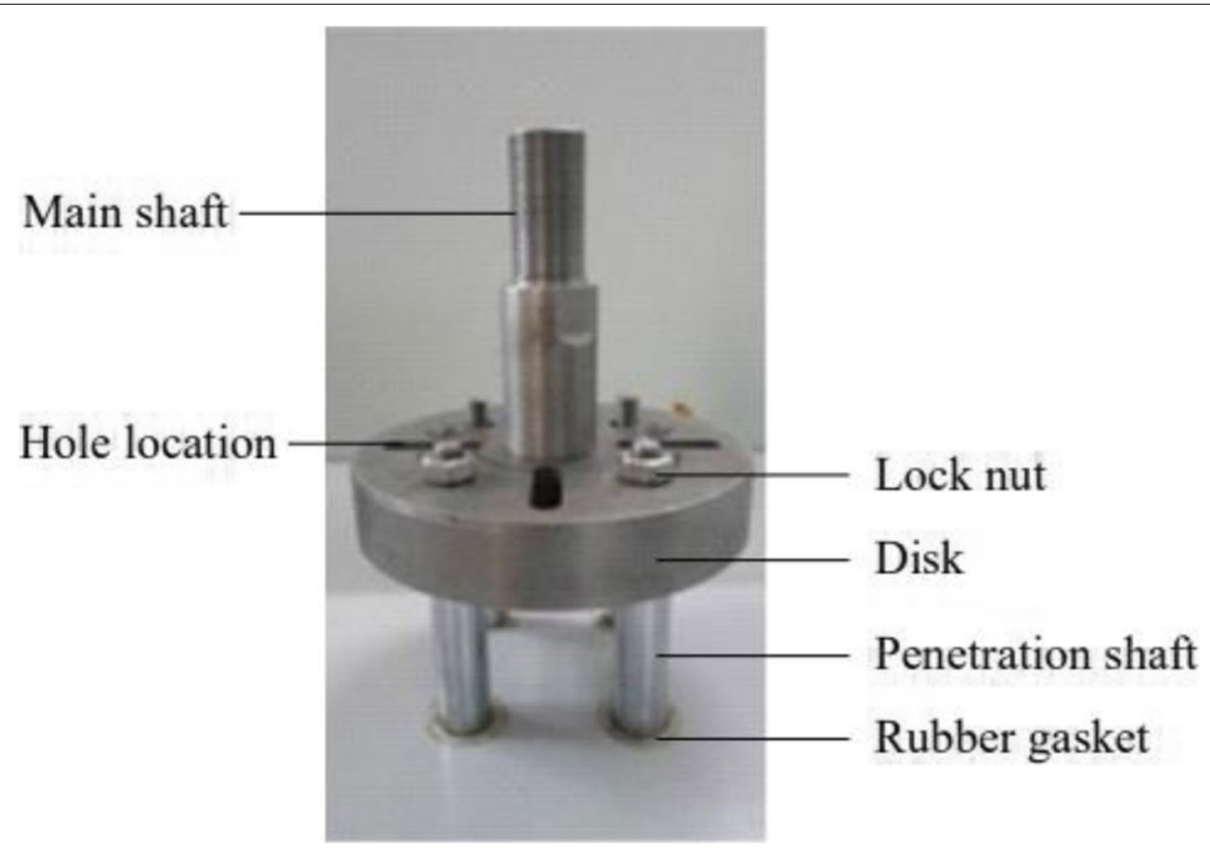

Fig. 2 Apparatus of the multi-point penetration test 


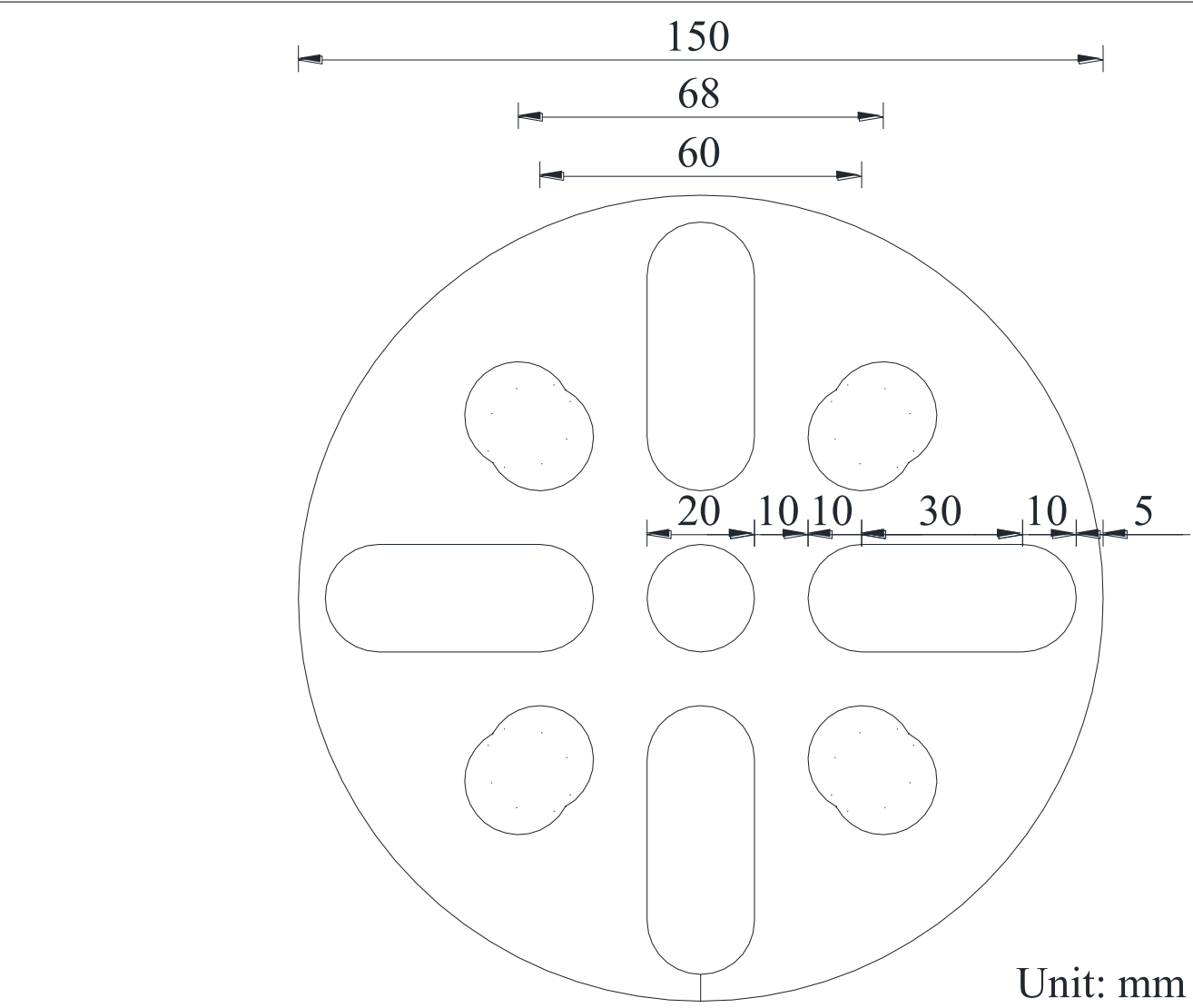

Fig. 3 Size of disk

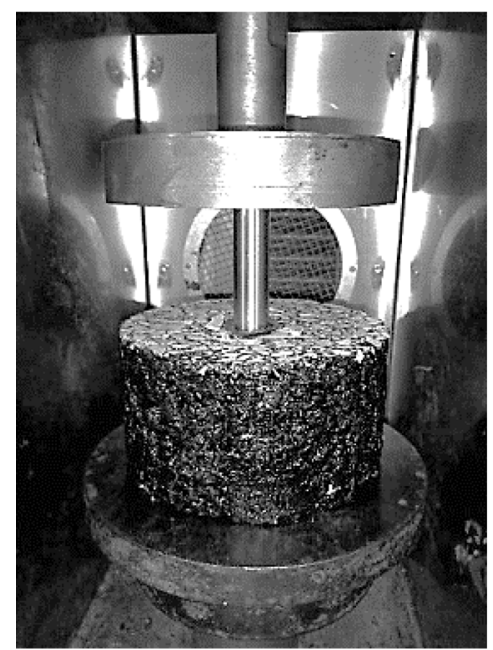

(a) Uniaxial penetration test

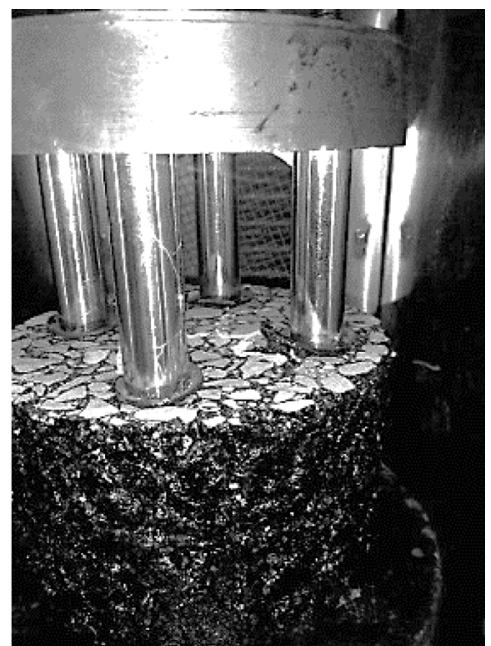

(b) Four-point penetration test

Fig. 4 Equipment installation of the penetration test. (a) Uniaxial penetration test. (b) Four-point penetration test 


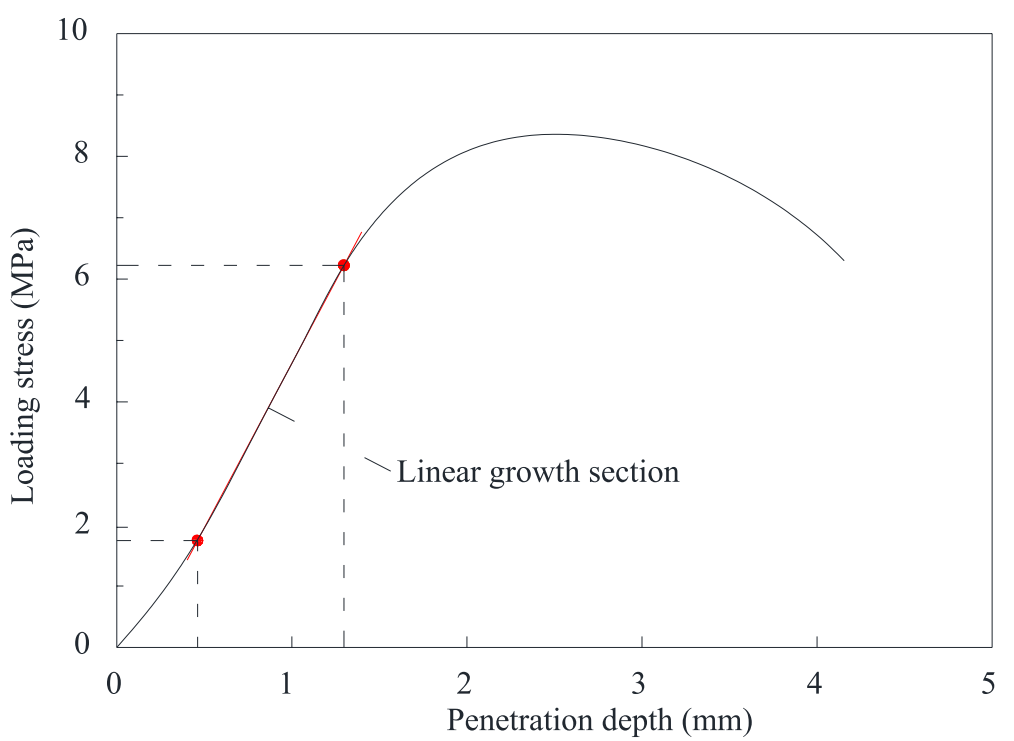

Fig. 5 Diagram of penetration curve

whereas the maximum value of four-point penetration is $0.65 \mathrm{MPa} / \mathrm{mm}$, which is only $59 \%$ of the former. This finding confirms the analysis in Failure mode of deformation superposition effect Section and indicates that the asphalt mixture is prone to deform under the four-point penetration load. Compared with the result under various four-point loads, the penetration load growth rate increases with wheel spacing. This phenomenon demonstrates the important effect of wheel spacing on superimposed deformation.

A direct explanation of the influence of wheel spacing on deformation superposition is illustrated in Fig. 10. Specifically, the superposition effect coefficient gradually increases with the rise of wheel spacing. For instance, the coefficient is 1.2 times higher for spacing of $54 \mathrm{~mm}$ compared with that for spacing of $65 \mathrm{~mm}$. The increase in the superposition effect coefficient suggests that the resistance to superposition deformation of asphalt mixture is better. This result is attributed to the increase in wheel spacing.

Table 4 Elastic and mass properties of particle materials in the discrete element model

\begin{tabular}{llllll}
\hline $\begin{array}{l}\text { Contact } \\
\text { stiffness } \\
(\mathbf{N} / \mathbf{m})\end{array}$ & $\begin{array}{l}\text { Connection } \\
\text { strength } \\
(\mathbf{N})\end{array}$ & $\begin{array}{l}\text { Adhesive } \\
\text { modulus } \\
\left(\mathbf{N} / \mathbf{m}^{2}\right)\end{array}$ & $\begin{array}{l}\text { Normal } \\
\text { shear } \\
\text { stiffness } \\
\text { ratio }\end{array}$ & $\begin{array}{l}\text { Friction } \\
\text { coefficient }\end{array}$ & $\begin{array}{l}\text { Density } \\
\left(\mathbf{k g} / \mathbf{m}^{3}\right)\end{array}$ \\
\hline $1 \times 10^{8}$ & $1 \times 10^{5}$ & $7.5 \times 10^{6}$ & 0.5 & 0.5 & 2780 \\
\hline
\end{tabular}

\section{Effect of the number of wheels}

The preliminary analysis in Failure mode of deformation superposition effect Section showed that the number of wheels is another important factor for the deformation superposition of the asphalt mixture. In this section, the deformation superposition effect under two-point, fourpoint, and six-point penetration loads was investigated. The test temperature was $60^{\circ} \mathrm{C}$, the loading rate was $1 \mathrm{~mm} / \mathrm{min}$, and the wheel spacing was $65 \mathrm{~mm}$. The results from the various number of wheels exhibit the variation of superposition parameters, as shown in Figs. 11 and 12 .

In Fig. 11, the penetration load growth rate is smaller under multi-point load compared with that under uniaxial load. This condition is the same as the previous analysis in Effect of wheel spacing Section. Figure 10 displays that the penetration load growth rate decreases with the number of wheels. The penetration load growth rate under uniaxial and six-point loads is 1.1 and $0.4 \mathrm{MPa} /$ $\mathrm{mm}$, and the latter decreases by $63.6 \%$. This finding shows that the number of wheels is an important parameter affecting the superimposed deformation of asphalt mixture, because it has the potential to increase the stress transferring path in the internal structure.

The deformation superposition effect coefficient varies with the number of wheels, as illustrated in Fig. 12. The superposition effect coefficient decreased with the growth number of wheels. The coefficient decreases from 0.66 in the case of two-point loading to 0.38 in the case of six-point loading, and the latter decreases by $42.9 \%$. This finding shows that the deformation superposition effect becomes significant with the increase of the number of wheels. The resistance of 


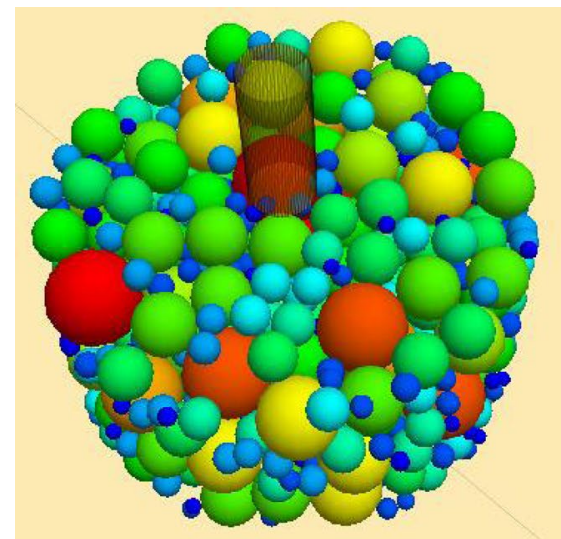

(a) Uniaxial penetration test model

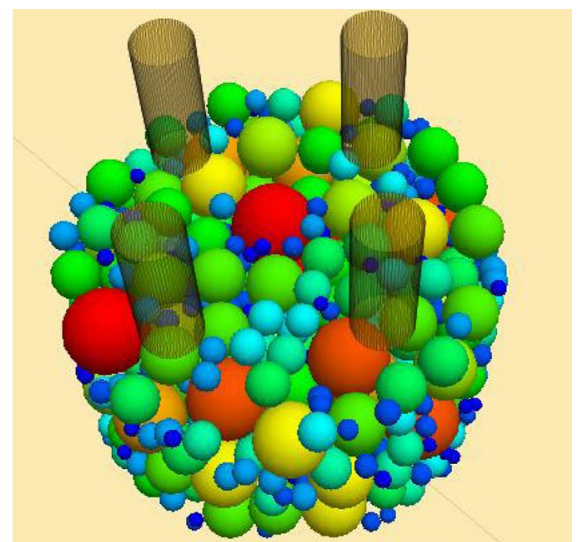

(b) Four-point penetration test model

Fig. 6 Penetration test model of asphalt mixture skeleton particles. (a) Uniaxial penetration test model. (b) Four-point penetration test model

asphalt mixture to deformation is reduced. Compared with light vehicles, we should pay attention to the multi-wheel heavy vehicles, which aggravate the possibility of superimposed deformation damage.

\section{Micromechanical characteristics of deformation superposition}

In Effect of the wheel group on deformation superposition Section, two factors causing the deformation superposition of asphalt mixture, namely, wheel spacing and the number of wheels, were discussed. They were the external reasons that cause the deformation superposition of the asphalt mixture. In the process of deformation, the variation of the micromechanical characteristics of asphalt mixture under multi-wheel load is still unclear. The importance of understanding the micromechanical characteristics is that it can guide asphalt mixture design for anti-superimposed deformation properties. Therefore, this section aims to clarify the micromechanical characteristics of deformation

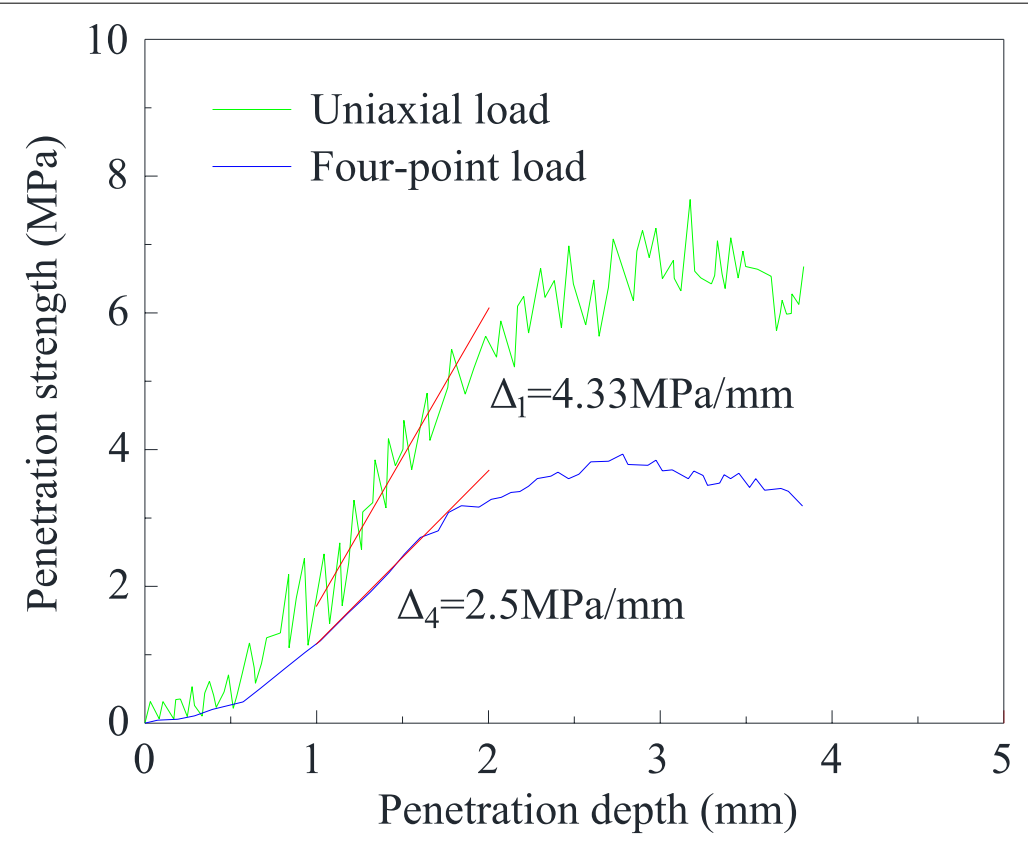

Fig. 7 Uniaxial and four-point penetration shear curves of SMA-13 mixture 


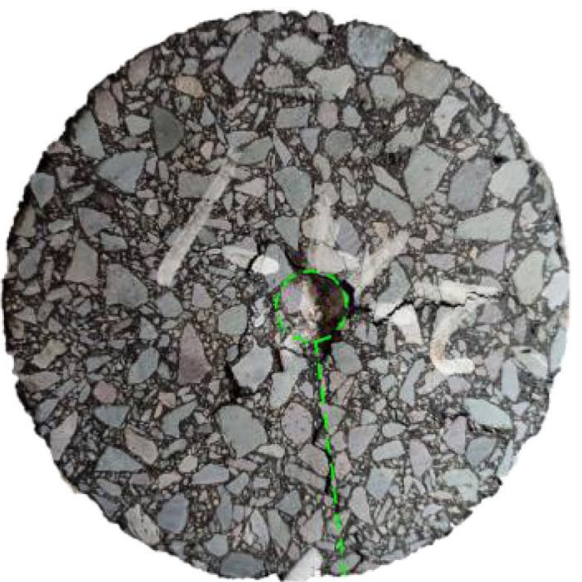

(a) Under the uniaxial load

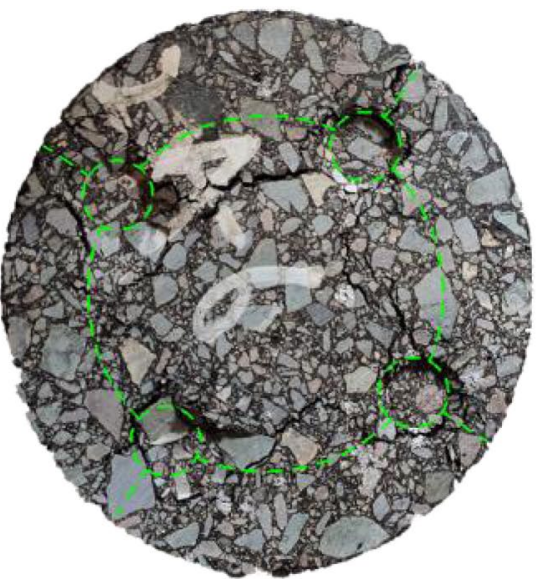

(b) Under the four-point load

Fig. 8 Crack patterns of SMA-13 mixture. (a) Under the uniaxial load. (b) Under the four-point load

superposition behavior under different wheel group conditions based on DEM.

\section{Wheel spacing}

In this section, the uniaxial and the four-point penetration tests with wheel spacings of 20,50, and $65 \mathrm{~mm}$ were simulated. The penetration curves are shown in Fig. 13. The black curve describes the result in the uniaxial penetration test, and the red, green, and purple curves describe the result under the wheel spacings of 20,50 , and $65 \mathrm{~mm}$.
As shown in Fig. 13, a linear relationship is found between penetration strength and depth, and the material mainly shows linear elastic characteristics at the initial stage of simulated loading. The mixture was destroyed until the load reached its peak, and the bearing capacity declined rapidly. The slope of the linear segment represents the penetration load growth rate. The slope and peak load are larger in uniaxial tests compared with that in multi-point tests. For instance, the former is 0.13 and $0.65 \mathrm{MPa}$, whereas, the maximum values of the latter are 0.12 and $0.35 \mathrm{MPa}$. This finding indicates that the

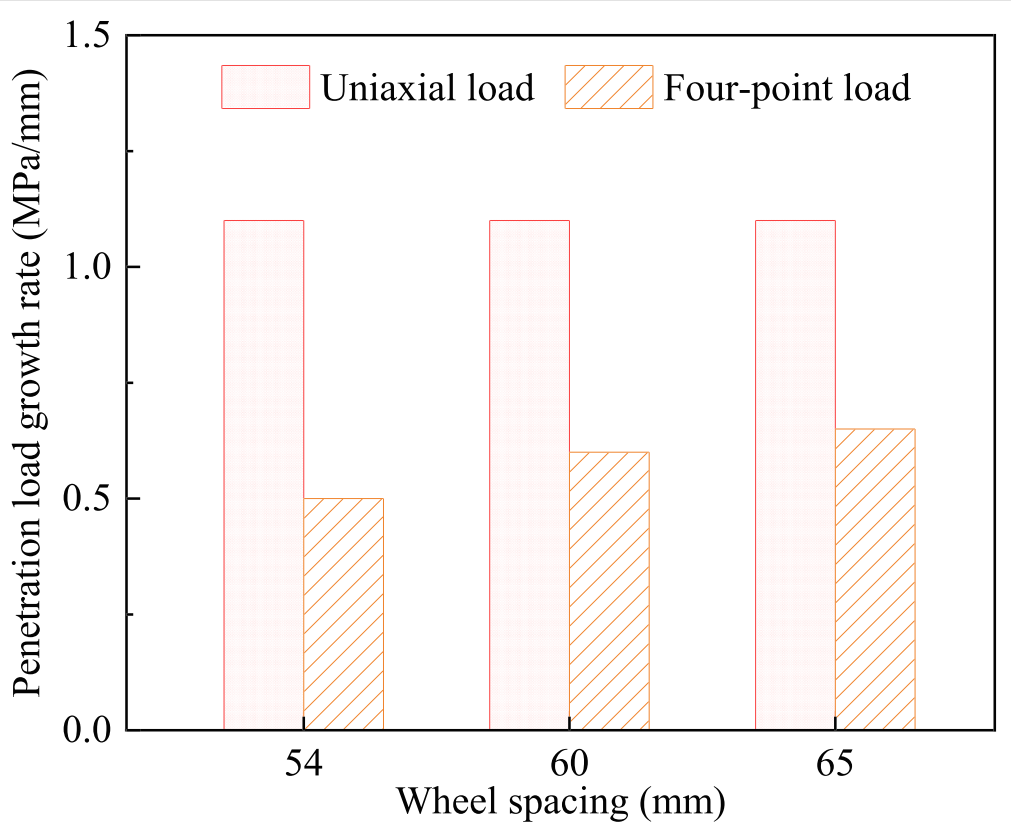

Fig. 9 Penetration load growth rate with different wheel spacings 


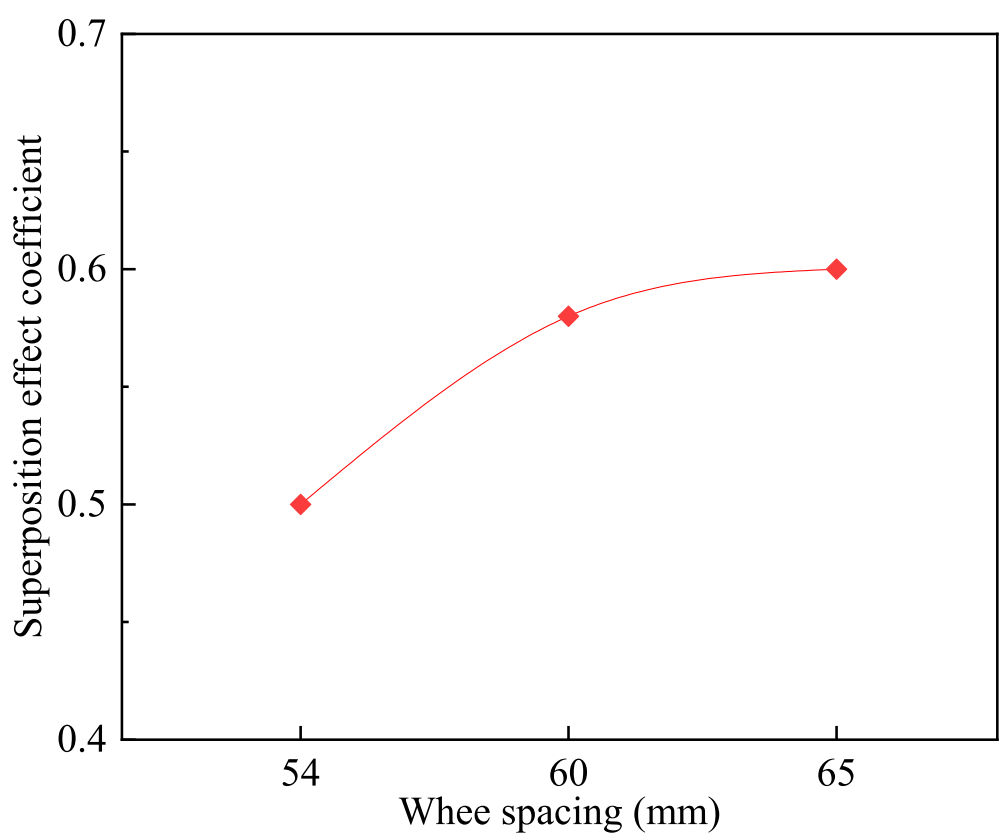

Fig. 10 Superposition effect coefficient with different wheel spacings

asphalt mixture consistently has low resistance to multiwheel action. The whole simulation loading process is consistent with the laboratory test, thereby reflecting the reliability and accuracy of the simulation. For multi-point simulation tests, the penetration load growth rate gradually increases with the increase in wheel spacing. The results agree with the reported laboratory test in Effect of wheel spacing Section.

The superposition effect coefficient obtained from the skeleton model is shown in Fig. 14. The values of the superposition effect coefficient are $0.43,0.55$, and 0.77 for the wheel spacing of 20,50 , and $65 \mathrm{~mm}$, respectively.

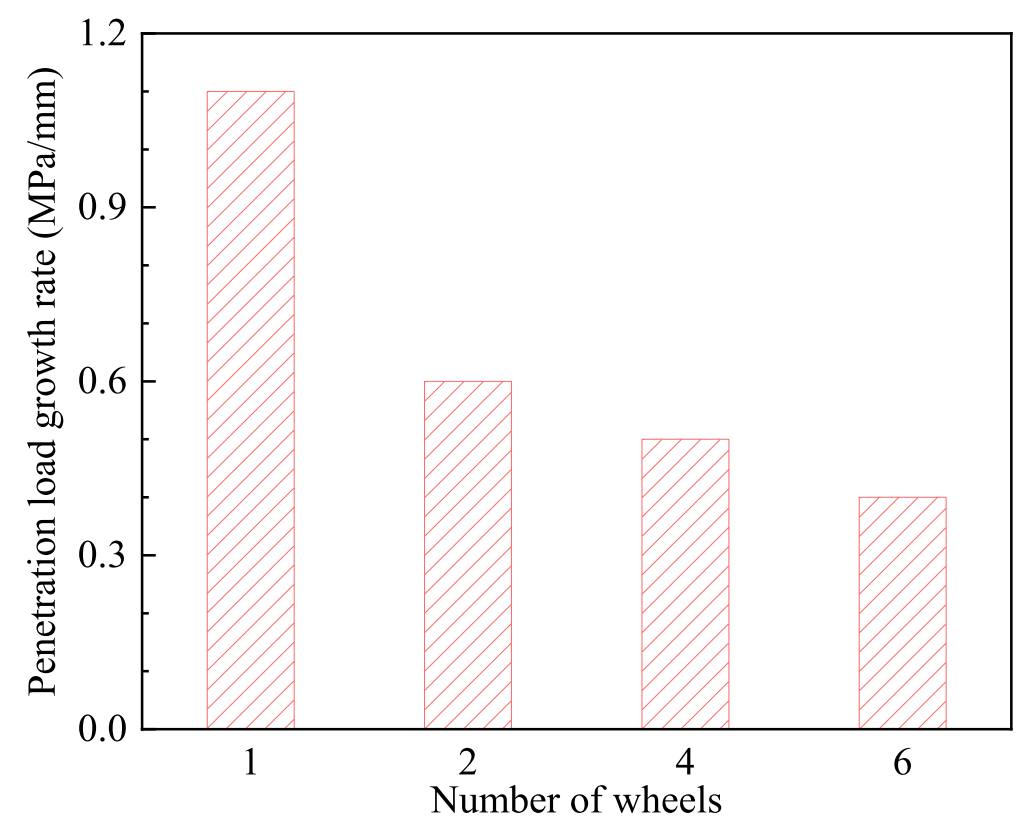

Fig. 11 Penetration load growth rate with different number of wheels 


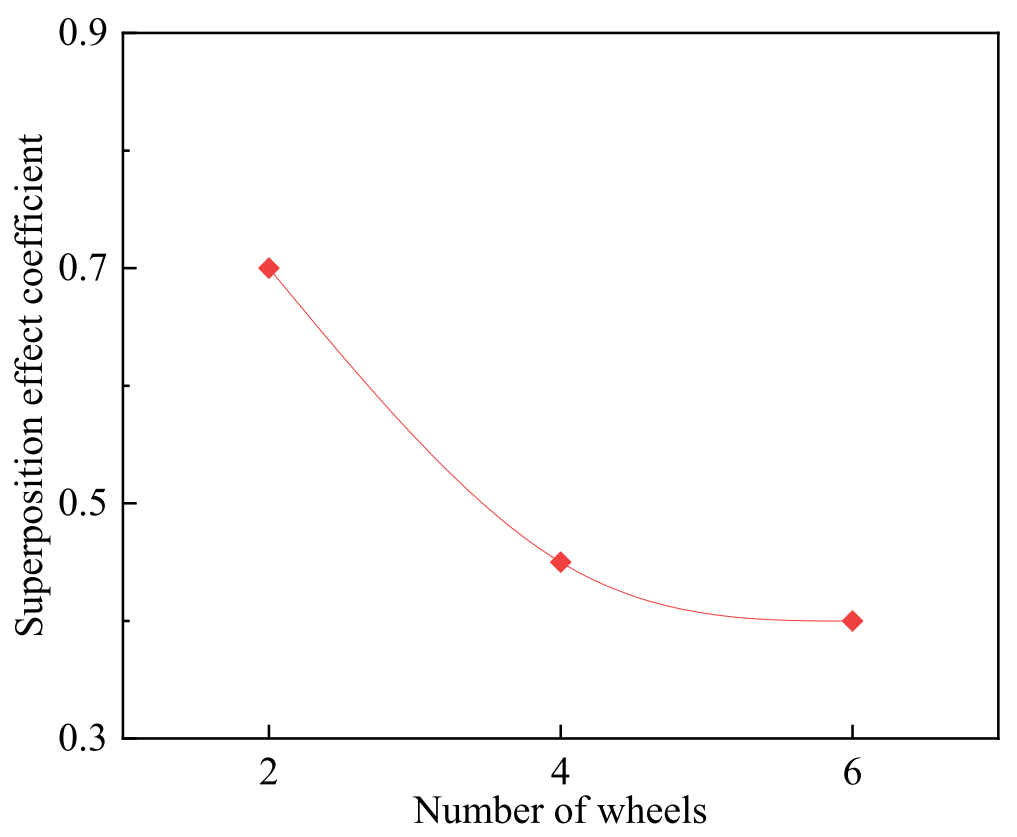

Fig. 12 Superposition effect coefficient with different number of wheels

This finding demonstrates that the model deformation under four-point loads is superimposed compared with that under uniaxial loads. The superposition coefficient increases with the decrease in wheel spacing. This result is the same as that obtained in Effect of wheel spacing Section.
Figure 15 shows that the number of tensile chains varies with depth. In the penetration process, the number of force chains gradually decreases. This phenomenon suggests that the strength of physical adhesion between the asphalt and the aggregate is reduced. As shown in Fig. 16, the decrement of tensile chains decreased with

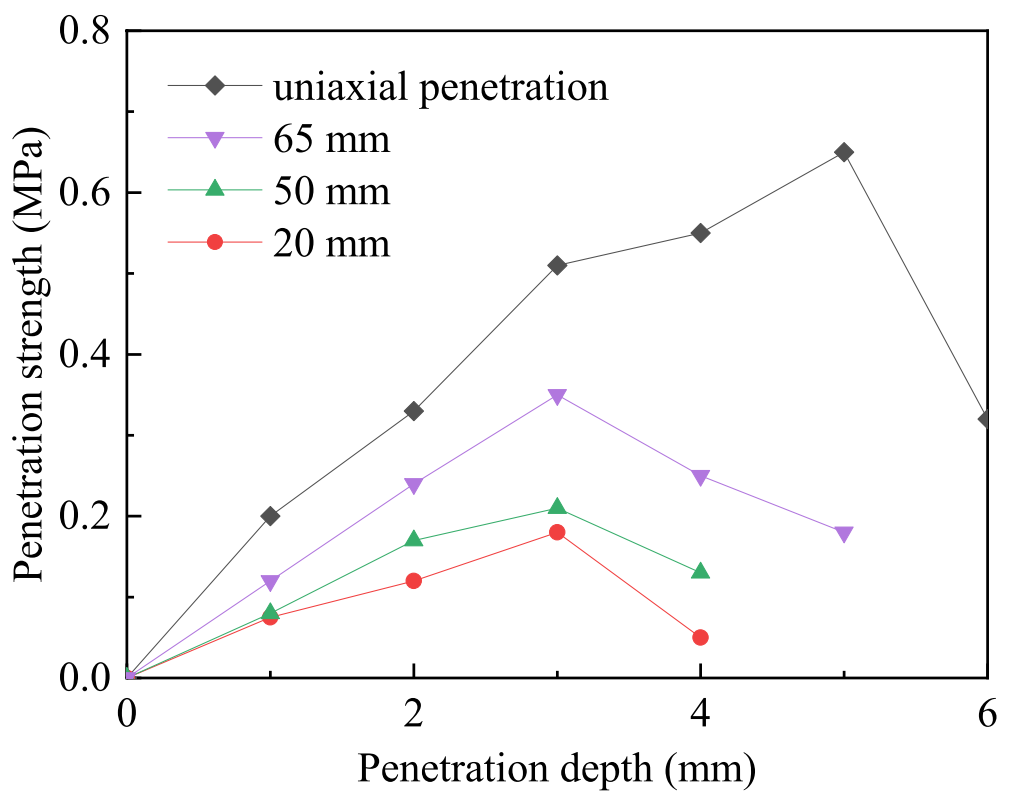

Fig. 13 Penetration curves with different wheel spacings 


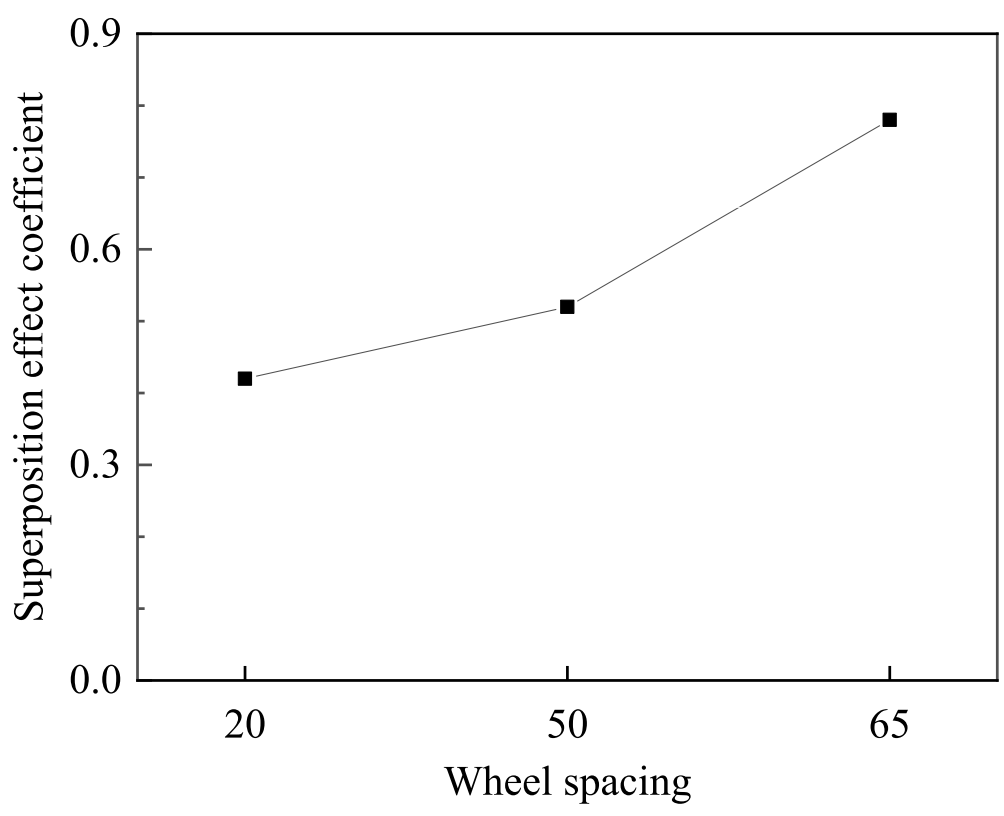

Fig. 14 Superposition effect coefficient at different wheel spacings

the increase in wheel spacing, the force chains at the penetration depth of $4 \mathrm{~mm}$ are reduced by 272,260 , and 249 for the wheel spacing of 20,50 , and $65 \mathrm{~mm}$ compared with that at $1 \mathrm{~mm}$. This result indicates further superimposed deformation and damage to the asphalt mixture.

The previous consequence can be illustrated by the force chain evolution in Fig. 17. The lines in the figure represent the contact force between the skeleton particles, and the blue and red lines denote the pressure and tensile chain, respectively.

During the whole loading process, the number of tensile chain decreases with the penetration depth. At the $1 \mathrm{~mm}$ penetration depth, the number of tensile chains reaches a maximum. At the $4 \mathrm{~mm}$ depth, a large number of tensile chains are broken. Under the four-point load, cracks are generated from the center to the edge of the model, and deformation superposition is destructive.

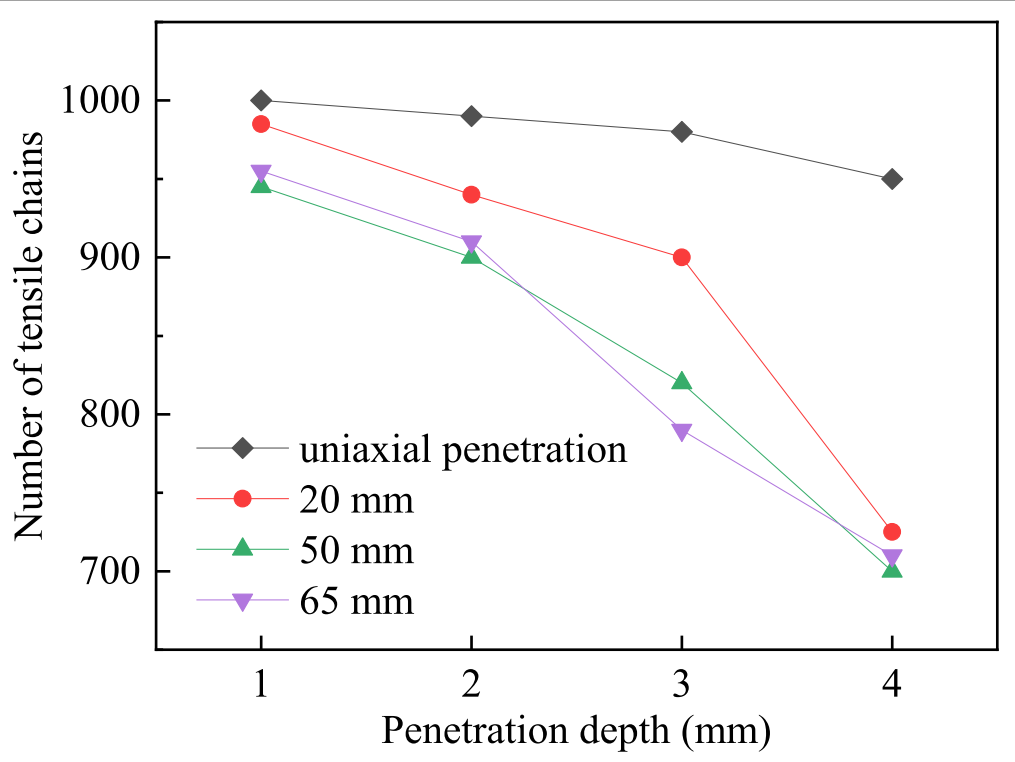

Fig. 15 Number of tensile chains at various depths 


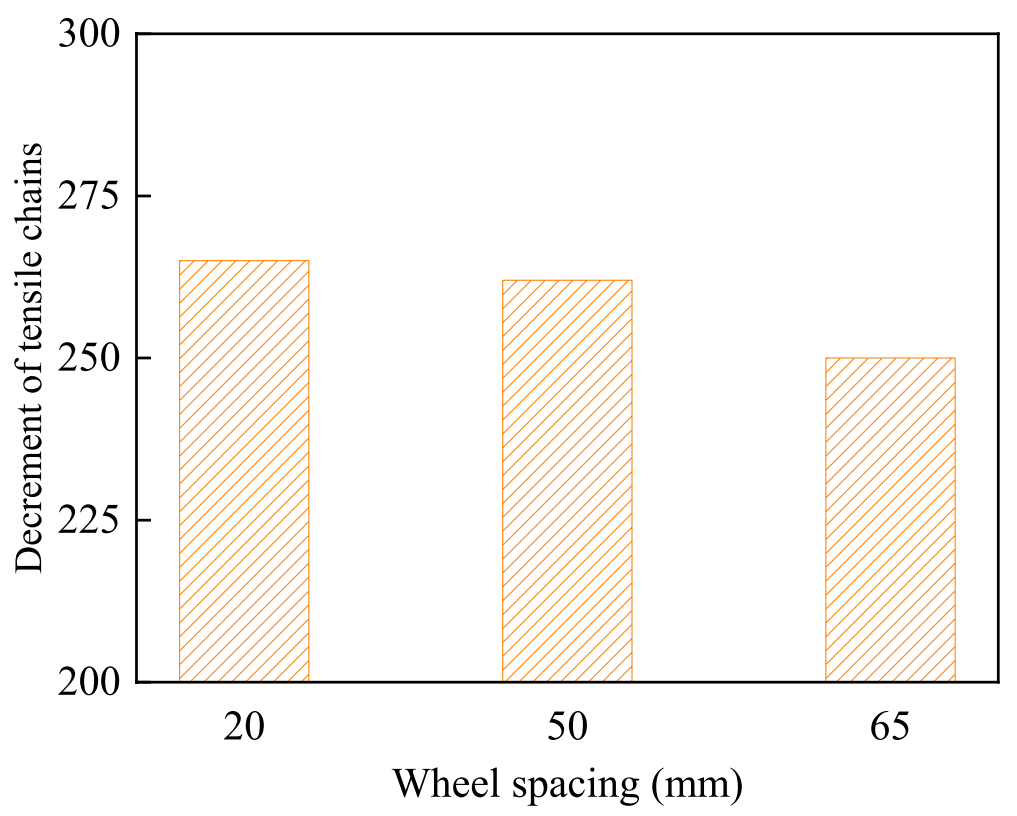

Fig. 16 Decrement of tensile chains with different wheel spacings

With the increase in wheel spacing, the number of tensile chains decreases significantly, and the skeleton model is close to the overall loading state. For the wheel spacing of $50 \mathrm{~mm}$, part of the tensile chain breaks at the edge of the model. For the wheel spacing of $65 \mathrm{~mm}$, only part of the force chain under the penetration shaft breaks. Under the four-point load, the number of broken tensile chains increases with the decrease in wheel spacing, and the superposition effect is significant.

\section{Number of wheels}

In this section, the uniaxial, two-point, four-point, sixpoint, and eight-point penetration tests were simulated. The penetration curves are shown in Fig. 18, and the superposition coefficient obtained from the skeleton model is shown in Fig. 18.

As shown in Fig. 18, the multi-point action has a significant effect on the deformation superposition behavior of the asphalt mixtures. This condition is consistent with the previous analysis in Number of wheels Section. With the increase in the number of penetration shafts, the peak load and penetration load growth rate of the model show a decreasing trend. Under the two-point, four-point, six-point, and eight-point loads, the former is $0.31,0.26,0.22$, and $0.16 \mathrm{MPa}$, and the latter is 0.078 , $0.065,0.073$ and $0.053 \mathrm{MPa} / \mathrm{mm}$, respectively. These results provide important insights into the superimposed deformation damage under multi-wheel load. As shown in Fig. 19, the superposition coefficient is 0.59,
$0.52,0.49$, and 0.41 in the aforementioned loading conditions. These results support the idea of the superposition effect being enhanced by multi-wheel load. This condition is consistent with the conclusion obtained in Effect of the number of wheels Section.

The results in Fig. 20 show the changes in internal tensile chains of the asphalt mixture during the deformation superposition. A significant reduction is found in tensile chains when the number of loads increased. As shown in Fig. 21, under the two-point, four-point, six-point, and eight-point loads, the number of force chains decreases at $4 \mathrm{~mm}$ is $203,250,307$, and 337 , respectively, compared with the peak value of tensile chains at the depth of $1 \mathrm{~mm}$. With the increase in the number of wheels, the number of tensile chains decreases significantly. This finding indicates that the more the number of wheels, the more serious the deformation and damage of asphalt mixture under multiwheel load. This result is consistent with the conclusion of the laboratory experiment above.

Figure 22 illustrates the variation of the force chain under the different number of wheels. The meaning of the lines in the figure is the same as in Wheel spacing Section.

At the same penetration depth, the high number of wheels corresponds to the low number of the tensile chain. The previous analysis in 3.2.2 indicates that the superposition coefficient of the skeleton model is smaller, the deformation superposition effect is more 

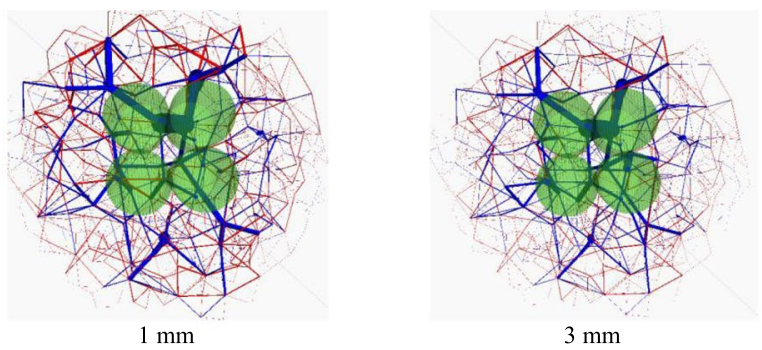

(a) Wheel spacing: $20 \mathrm{~mm}$
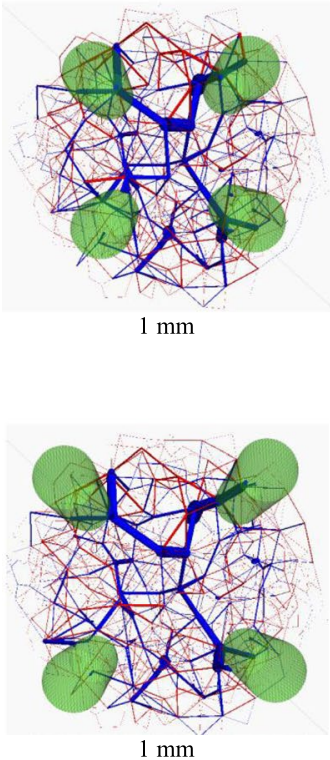

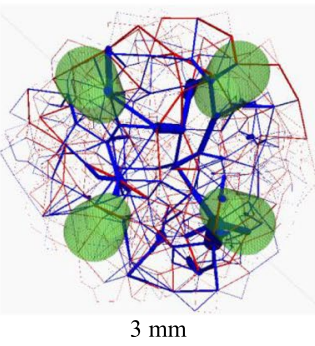

(b) Wheel spacing: $50 \mathrm{~mm}$

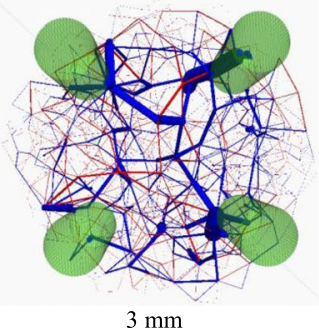

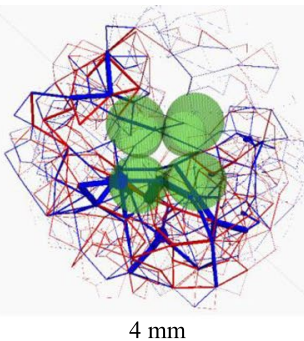

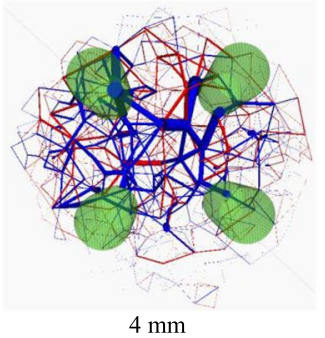

$4 \mathrm{~mm}$

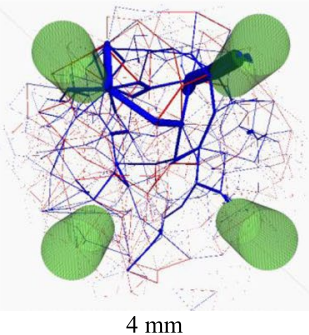

(c) Wheel spacing: $65 \mathrm{~mm}$

Fig. 17 Distribution of force chains under different wheel spacings. (a) Wheel spacing: $20 \mathrm{~mm}$. (b) Wheel spacing: $50 \mathrm{~mm}$. (c) Wheel spacing: $65 \mathrm{~mm}$

significant, and asphalt mixtures have weak resistance to deformation.

Specifically, for the uniaxial penetration test, the number of tensile chains is 1006 at a penetration depth of $1 \mathrm{~mm}$, and the skeleton model has strong resistance to deformation superposition. This condition is the reason that the shear stress of the whole skeleton structure points to the external, and the full skeleton structure shares shear deformation. Thus, tensile chains are found. When the penetration depth reaches $4 \mathrm{~mm}$, the number of tensile chains in the skeleton model decreases remarkably. Under the eight-point load, the number of tensile chains of the skeleton model is 893 at the depth of $1 \mathrm{~mm}$, whereas the number of tensile chains of the skeleton model rapidly decreases at the depth of $4 \mathrm{~mm}$. Affected by the superposition effect, the tensile chains of the skeleton model near the penetration shaft decrease, and the bearing capacity of the structure decreases rapidly. Under the eight-point load, the number of tension chains at different penetration depths is the minimum, and the asphalt mixture has poor resistance to structure deformation.

\section{Conclusions}

This study focused on the deformation superposition behavior of asphalt mixture and its micromechanical characteristic. The multi-point penetration tests were employed. The influences of wheel spacing and the number of wheels were investigated, respectively. Based on the DEM, the micromechanism of deformation superposition behavior under different wheel spacing and the number of wheels were further studied. The main conclusions are summarized as follows.

The penetration load growth rate and superposition effect coefficient were adopted to quantitatively 


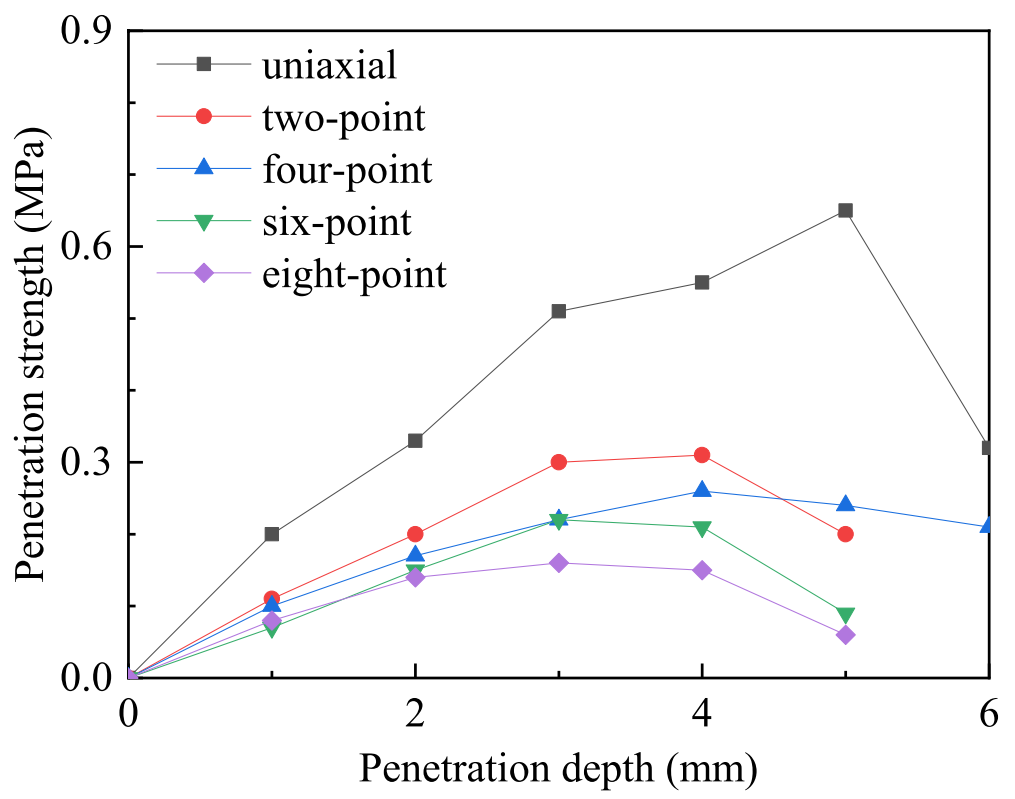

Fig. 18 Penetration curves with different numbers of wheels

evaluate the deformation superposition characteristics in asphalt mixture. It was found that the penetration load growth rate and superposition effect coefficient are decreased under the intensifying of multi-wheel action. Specifically, these two parameters increase with wheel spacing, while those decrease with the number of wheels. This result indicates that the deformation superposition effect is significant under the multi-wheel load. From a failure mode perspective, the reason for this is because the action of multi-wheel load increases stresses transferring path in the internal structure of asphalt mixture.

Micromechanical analysis based on virtual penetration tests shows that the tensile forces within asphalt mixture tend to decrease during multi-point penetration tests. The deformation superposition effect of asphalt mixture

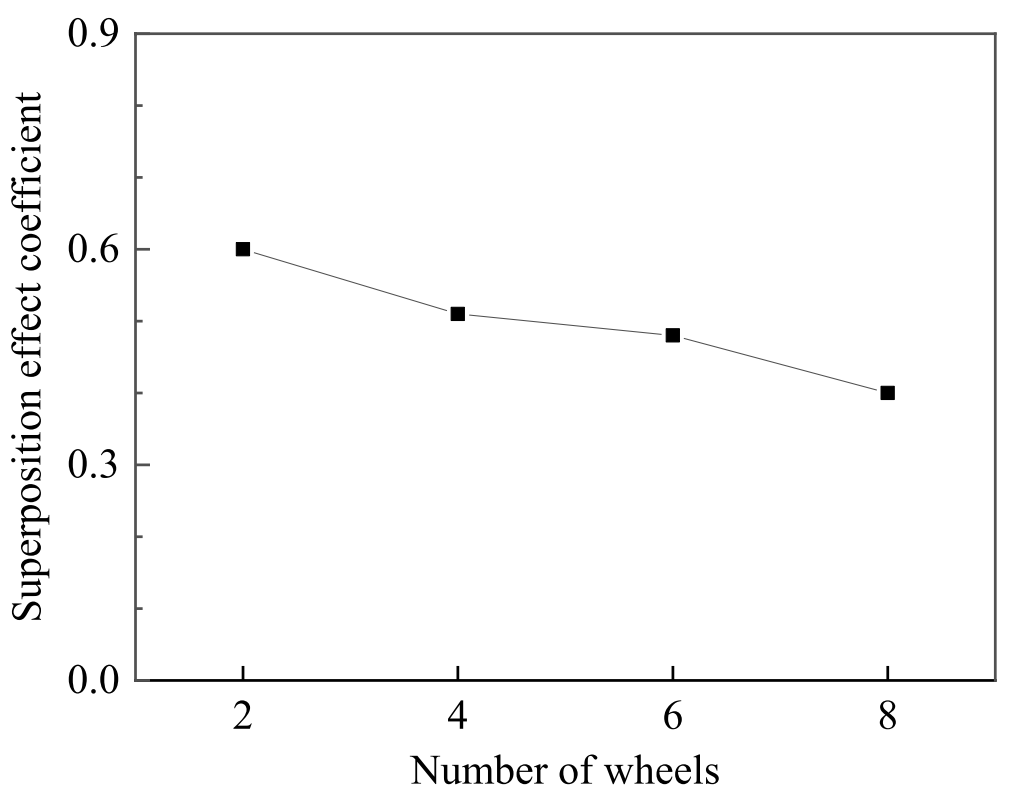

Fig. 19 Superposition effect coefficient with different numbers of wheels 


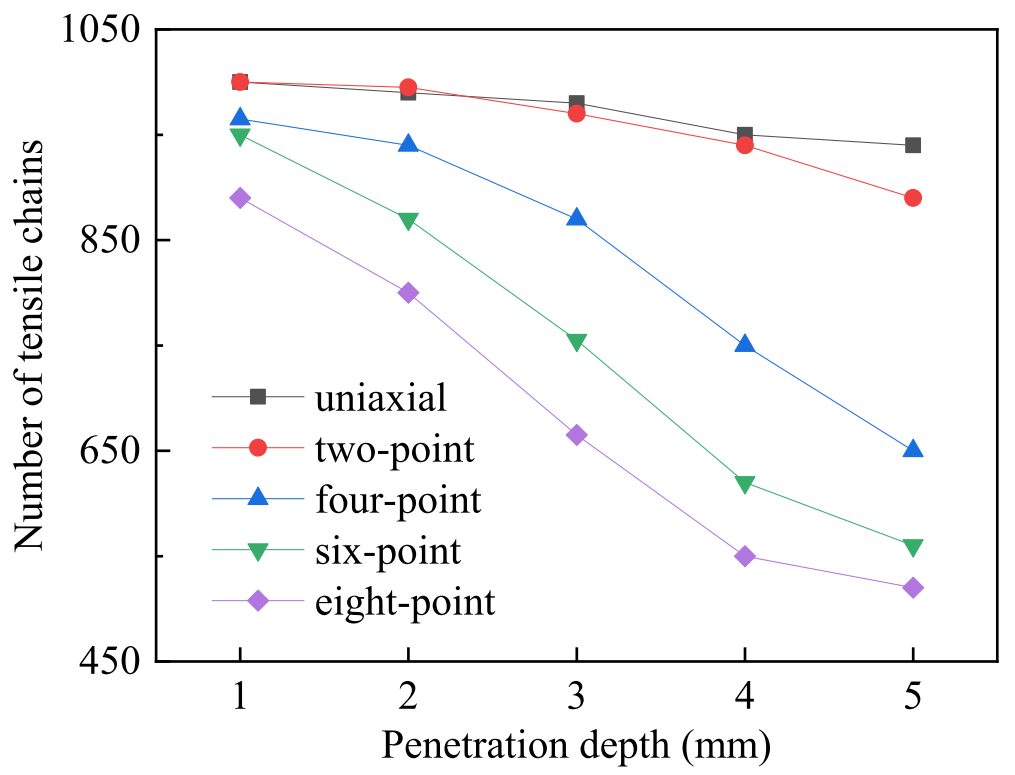

Fig. 20 Number of tensile chains with different numbers of wheels

can be described by using the deformation superposition effect coefficient and reduction of the tensile chain in skeleton model. The discrete element model was used to verify the deformation superposition characteristics of the asphalt mixture under different factors. The results show that the deformation superposition effect coefficient of the skeleton model decreased with the wheel spacing and the number of wheels. The greater the reduction of the tensile force chain, the greater the superimposed deformation, and the deformation superposition effect coefficient is negatively correlated with the reduction of the tensile chain. The tensile chain represents the adhesive strength between aggregates in asphalt mixture, thus, the intrinsic reason for deformation superposition is the decrease of the adhesive strength of the material.

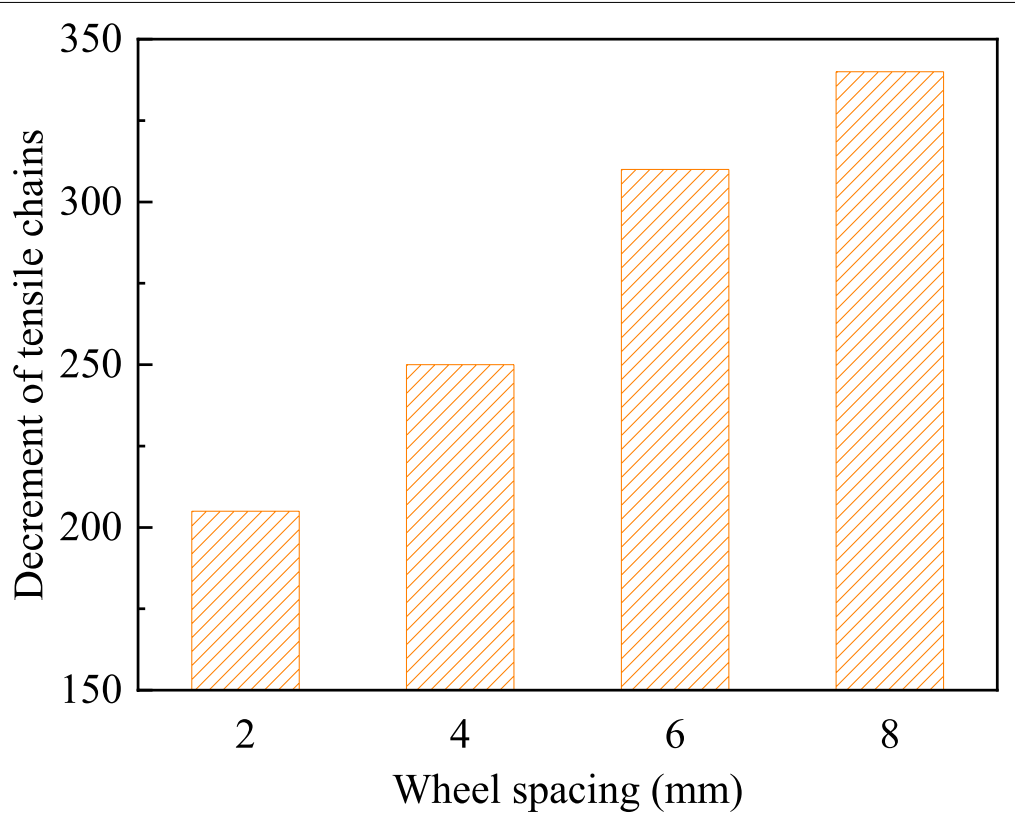

Fig. 21 Decrement of tensile chains with different numbers of wheels 

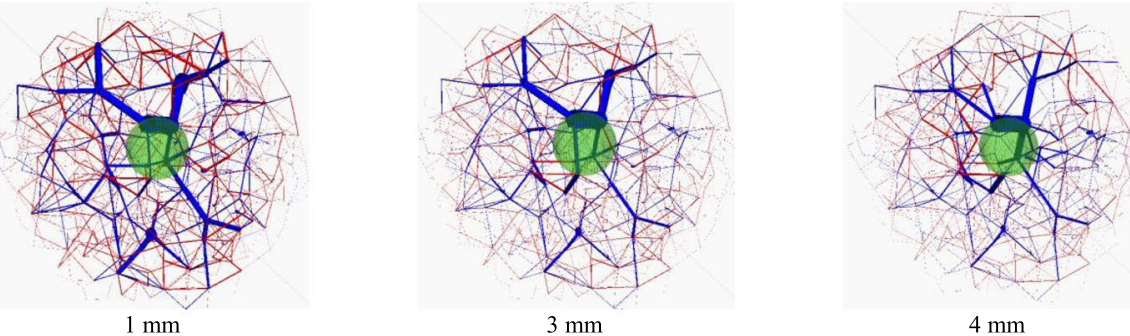

(a) Number of the wheels: 1
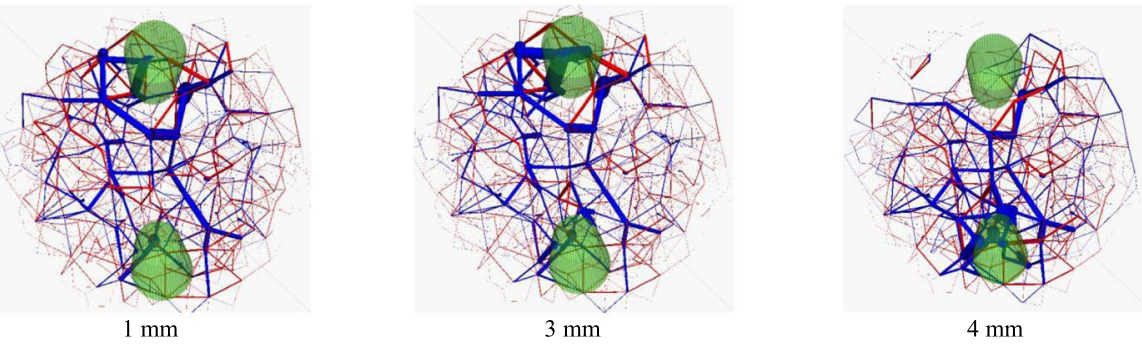

(b) Number of the wheels: 2
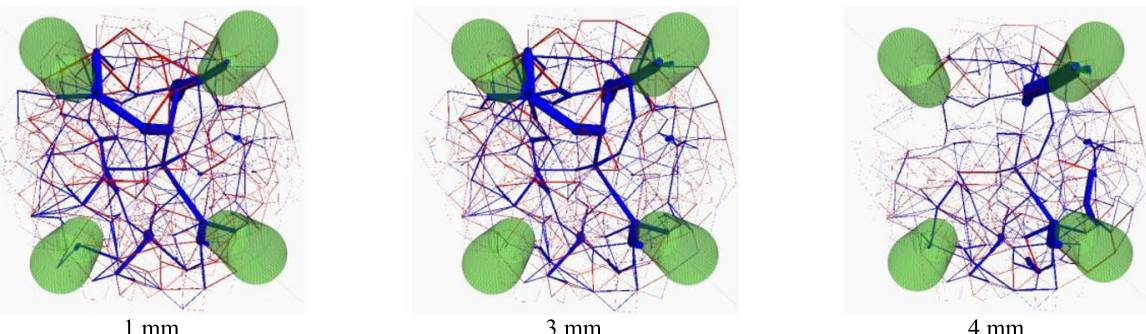

$4 \mathrm{~mm}$

(c) Number of the wheels: 4
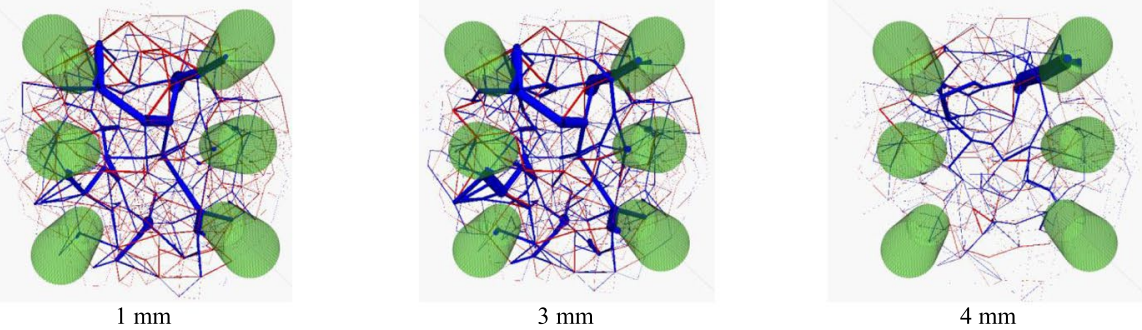

(d) Number of the wheels: 6

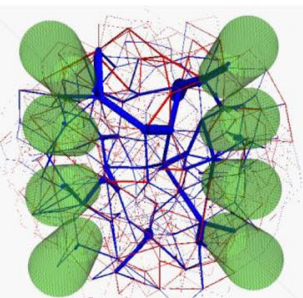

$1 \mathrm{~mm}$

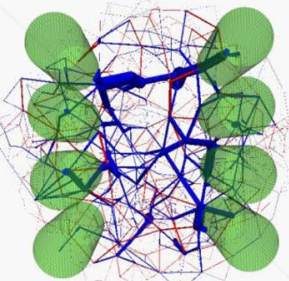

$3 \mathrm{~mm}$

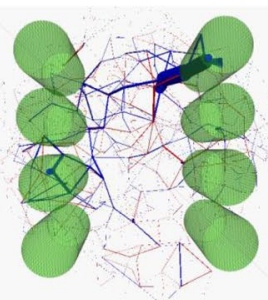

$4 \mathrm{~mm}$

(e) Number of the wheels: 8

Fig. 22 Distribution of tensile chain under the different number of the wheels. (a) Number of the wheels: 1. (b) Number of the wheels: 2. (c) Number of the wheels: 4. (d) Number of the wheels: 6. (e) Number of the wheels: 8 


\section{Abbreviations}

DEM: Discrete element method; SMA: Stone matrix asphalt; UTM: Universal testing machine; $\Delta_{1}$ : Penetration load growth rate under the uniaxial load; $\Delta_{n}$ : Penetration load growth rate under the multi-point load; $\Delta_{4}$ : Penetration load growth rate under the four-point load; $\beta_{\Delta}$ : Superposition effect coefficient.

\section{Acknowledgements}

The author acknowledges the editorial assistance and the constructive criticism by anonymous reviewers.

\section{Authors' contributions}

$\mathrm{CL}$ initiated the project and conceptualization. XB collected and synthesized references, drafted and wrote the manuscript. QD proposed the experimental program, conducted laboratory tests and modeling. HX developed the research plan, reviewed and edited the manuscript. The authors read and approved the final manuscript.

\section{Funding}

Financial support from National Key Research and Development Program of China (Grant No. 2018YFB1600203), Excellent Youth Project of Natural Science Foundation of Heilongjiang (Grant No. YQ2019E019), and Excellent Youth Science fund Project of National Natural Science Foundation of China (Grant No. 51922035) is gratefully acknowledged.

\section{Availability of data and materials}

All data used or generated by this study is available from the corresponding author by reasonable request.

\section{Declarations}

\section{Ethics approval and consent to participate}

Not applicable.

\section{Consent for publication}

Not applicable.

\section{Competing interests}

The authors declare that they have no competing interests.

\section{Author details}

1 Petro China Fuel Oil Limited Research Institute, Beijing 100195, China. ${ }^{2}$ School of Transportation Science and Engineering, Harbin Institute of Technology, Harbin 150090, China.

Received: 29 July 2021 Accepted: 22 September 2021

Published online: 15 October 2021

\section{References}

1. Hajek JJ, Agarwal AC (1990) Influence of axle group spacing on pavement damage. Trans Res Record J Trans Res Board 1286:138-149

2. Li Q, Liu D, Sun J, Lu J (2014) Influence of heavy axle load on dynamic response of semi-rigid base of asphalt pavement. Applied mechanics and materials 505-506:72-76. https://doi.org/10.4028/www.scientific.net/ AMM.505-506.72

3. Kabir R, Hiller JE (2019) Numerical analyses of rigid and flexible pavements responses under heavy vehicles' loading. Road materials and pavement design 2:1-24. https://doi.org/10.1080/14680629.2019. 1621189

4. Ilves GJ, Majidzadeh K (1989) Reevaluation of the methods for calculation of load equivalency and damage ratios, Research report. Resource International Inc, Westerville

5. Jason $L$ (2011) Effects of heavy agricultural vehicle loading on pavement performance, Master thesis. The University of Minnesota, Twin Cities

6. Gomezramirez F (2002) Characterizing aircraft multiple load interaction for airport flexible pavement design, Ph.D. dissertation. University of Illinois at Urbana-Champaign, Urbana-Champaign
7. Hayhoe GF, Garg N, Dong M (2004) Permanent deformations during traffic test on flexible pavement at the national airport pavement test facility. Airfield pavements specialty conference 2003:147-169. https:// doi.org/https://doi.org/10.1061/40711(141)10

8. Gopalakrishnan K (2002) Performance analysis of airport flexible pavement subjected to new generation aircraft, Ph.D. dissertation. University of Illinois at Urbana-Champaign, Urbana-Champaign

9. Al-Qadi IL, Portas S, Coni M, Lahouar S (2010) Runway instrumentation and response measurements. Transportation Research Board 89th annual meeting:162-169. https://doi.org/https://doi.org/10.3141/2153-18

10. Fabre C, Balay JM, Lerat P, Mazars A (2009) Full-scale aircraft tire pressure tests. Bearing capacity of roads, Railways \& Airfields International Conference:1-11. http://worldcat.org/isbn/9780415871990

11. Salama HK, Chatti K, Lyles RW (2006) Effect of heavy multiple axle trucks on flexible pavement damage using in-service pavement performance data. J Transp Eng 132(10):763-770 https://doi.org/0733-947X(2006)132: 10<763:EOHMAT>2.0.TX;2-1

12. Zhao H, Ling J, Yao Z (2010) Study on pavement superposition effects under multiple aircraft tires. GeoShanghai 2010 International Conference:546-551. https://doi.org/https://doi.org/10.1061/41104(377)70

13. Minkwan K, Erol T (2008) Multiple wheel-load interaction in flexible pavements. Trans Res Record J Trans Res Board 2068(1):49-60. https://doi.org/ 10.3141/2068-06

14. Thompson MR, Garg N (1999) Wheel load interaction: critical airport pavement responses, Ph.D. dissertation. University of Illinois at UrbanaChampaign, Urbana-Champaign

15. Thompson MR, Garg N (1999) Wheel load interaction: critical airport pavement responses. Proceedings of the Federal Aviation Administration airport technology transfer conference:22-31

16. Zhao Y, Wang G, Wang Z (2011) Research on structural design method of asphalt pavement based on multiple indexes: a study report on traffic load parameters and equivalent axial load conversion, Research report. Ministry of Transport of the People's Republic of China, Beijing

17. Martin TC (2011) Experimental estimation of the relative deterioration of flexible pavements under increased axle loads. Int J Pavement Eng 12(1):37-45. https://doi.org/10.1080/10298431003749717

18. Marques Almeida AM, Santos LG de P (2015) Methodological framework for truck-factor estimation considering vehicle-pavement interaction. J Transp Eng 141(2):04014074. https://doi.org/10.1061/(ASCE) TE.1943-5436.0000726

19. Chatti K, Manik A, Salama H, Haider SW, Brake N, El Mohtar C (2009) Effect of Michigan multi-axle trucks on pavement distress: volume I-literature review and analysis of in-service pavement performance data. Research report. Department of Civil and Environmental Engineering of Michigan State University, Lansing

20. Homsi F, Bodin D, Yotte S, Breysse D, Balay JM (2011) Multiple axle loadings shape parameters and their effect on the fatigue life of asphalt mixtures. Eur J Environ Civ Eng 15(5):743-758. https://doi.org/10.3166/ ejece.15.743-758

21. You Z, Buttlar WG (2004) Discrete element modeling to predict the modulus of asphalt concrete mixtures. J Materials Civil Eng 16(2):140-146. https://doi.org/10.1061/(ASCE)0899-1561(2004)16:2(140)

22. Zelelew HM (2008) Simulation of the permanent deformation of asphalt concrete mixtures using discrete element method. Ph.D. dissertation. Washington State University, Pullman

23. Chen J, Zeng L, Yin J (2013) Discrete element method (DEM) analyses of hot-mix asphalt (HMA) mixtures compaction and internal structure. Adv Mat Res 639-640:1287-1294. https://doi.org/10.4028/www.scientific. net/AMR.639-640.1287

24. Chen J (2011) Discrete element method (DEM) analyses for hot-mix asphalt (HMA) mixture compaction, Ph.D. dissertation. The University of Tennessee, Knoxville

25. Bouchaud JP, Cates ME, Claudin P (1995) Stress distribution in granular media and nonlinear wave equation. J de Physique I 5(6):639-656. https://doi.org/10.1051/jp1:1995157

26. Wittmer JP, Cates ME, Claudin P (1996) Stress propagation and arching in static sandpiles. Journal de Physique I 7(1):39-80. https://doi.org/10. 1051/jp1:1997126

27. Tordesillas A, Shi J, Tchaikovsky T (2011) Stress-dilatancy and force chain evolution. Int J Numer Anal Methods Geomech 35(2):264-292 https:// doi.org/10.1002/nag.910 
28. Tordesillas A, Pucilowski S, Sibille L, Nicot F, Darve F (2012) Multiscale characterization of diffuse granular failure. Philos Mag 92(36):4547-4587 https://doi.org/10.1080/14786435.2012.715766

29. Wang D, Zhou Y (2010) Statistics of contact force network in dense granular matter. Particuology 8(2):133-140 https://doi.org/10.1016/j. partic.2009.09.007

30. You Z, Buttlar W (2006) Micromechanical modeling approach to predict compressive dynamic moduli of asphalt mixtures using the distinct element method. Trans Res Record J Trans Res Board 1970:73-83 https://doi. org/10.3141/1970-09

31. Liu Y, You Z (2009) Visualization and simulation of asphalt concrete with randomly generated three-dimensional models. J Comput Civ Eng 23(6):340-347 https://doi.org/10.1061/(ASCE)0887-3801(2009)23:6(340)
32. Xu Y, Sun L (2013) Study on permanent deformation of asphalt mixtures by single penetration repeated shear test. Procedia Soc Behav Sci 96(1):886-893 https://doi.org/10.1016/j.sbspro.2013.08.101

33. Wang $\mathrm{H}$ (2015) The superposition effect of high-temperature deformation of asphalt pavement under aircraft multi-wheel load. Ph.D. dissertation. Harbin Institute of Technology, Harbin

34. Sun L (2005) Structure behavior study of asphalt pavements. China Communications Press, Beijing

\section{Publisher's Note}

Springer Nature remains neutral with regard to jurisdictional claims in published maps and institutional affiliations.

\section{Submit your manuscript to a SpringerOpen ${ }^{\circ}$ journal and benefit from:}

- Convenient online submission

- Rigorous peer review

- Open access: articles freely available online

- High visibility within the field

- Retaining the copyright to your article

Submit your next manuscript at $\gg$ springeropen.com 